\title{
Computerphobia in Preservice Teachers
}

\author{
Vehbi Aytekin Sanalan ${ }^{1}$ \\ ${ }^{1}$ Faculty of Education, Erzincan University, Erzincan, Turkey \\ Correspondence: Vehbi Aytekin Sanalan, Egitim Fakultesi, Erzincan Universitesi, Yalnizbag Yerleskesi, Erzincan, \\ Turkey Tel: 90-446-224-0089. E-mail: sanalan@erzincan.edu.tr
}

\author{
Received: August 19, 2015 Accepted: October 9, 2015 Online Published: February 25, 2016 \\ doi:10.5539/ies.v9n3p217 URL: http://dx.doi.org/10.5539/ies.v9n3p217
}

\begin{abstract}
This study proposes an instrument to determine and categorize computerphobia in college students, and reports findings from implementation of this instrument on education majors in a northeastern university in Turkey. 829 teacher education students were administered computerphobia scale (CPS) after they attended an introductory computer course. Factor analysis, CFA and GLM methods are utilized for data analysis. Results indicate a reliable instrument and significant differences for gender, computer ownership, and computer experiences. Females had significantly higher CPS scores. Computer ownership and experience with computers reversely related to computerphobia. It is recommended to expose teacher candidates more to computer-using opportunities and carefully designed computer education arrangements.
\end{abstract}

Keywords: computerphobia, pre-service teachers, computer experience, gender, computer education

\section{Introduction}

Individuals as well as societies diversely respond towards technological improvements and their implementations. Some undergo a plausible adaptation of new technologies while others develop neutral to negative emotional reactions such as resistance, anxiety or phobia. Attitudes towards computers are directly related to the effective use, and in turn, the productivity of the workplace in the computer era.

Computer anxiety has been abundantly studied over the last three decades by researchers from different cultures (Korobili, Togia, \& Malliari, 2010; Arigbabu, 2006). Early reports recognized the negative psychological and cognitive reactions toward computers, but fail to distinct users' deep anxiety from phobic reactions (Todman \& Day, 2006).

\subsection{Computer Anxiety}

Bourne (2005) describes anxiety as "...subjective state of apprehension or uneasiness" (p. 5), while the definition of phobia is "...a persistent and unreasonable fear of a specific object, activity or situation..." (p. 46). People feel safer as long as they avoid the experiences that make them anxious. It is different from everyday fear of an object when the avoidance is persistent and unreasonable. Apparently, anxiety occurs internally and is a physiological, behavioral and psychological response that may lead to observable bodily reactions.

Phobia, on the other hand, is more external and directed toward actual objects or situations. According to Bourne (2005) anxiety disorders may lead to phobia when the person actually "avoids" the situation and this affects person's everyday life. Despite the psychological distinction of anxiety and phobia, researchers use the terms computerphobia and computer anxiety interchangeably (Agbatogun \& Banjo, 2010; Baloglu \& Cevik, 2009, Hudiburg, 1990). For some, it is an anxiety about using computers (Lynn, 1989) or thinking about using computers (King, Bond, \& Blandford, 2002). However, it is important to emphasize that computer-related stress is different from computerphobia (Hudiburg, 1990).

Rosen and Weil (1995) define computer anxiety as fear or anxiety about computers, resistance to talk about computers, and hostile or aggressive thoughts about them. Computer related anxiety is usually considered to be a latent variable in measuring computerphobia. Since a phobia is more concrete and directed towards real objects, it is concluded that a person's fear of computers can be attributed to their self-report statements. Fear of computers is a concept that can be identified and measured better since it is focused more on the actual object, rather than internal reactions. Computerphobia may eventually lead to more serious computer disorders and this in turn decreases productivity in our modern society. A person with computerphobia decreases his chance of 
employment, as well. Moreover, it is commonly accepted that people need to work with computers in almost every aspect of their life (Levine \& Donitsa-Schmidt, 1997).

\subsection{Indicators of Computer Anxiety}

The indicators of computer anxiety can be pinpointed by biological changes, behavioral observations, and self-reported data. Beckers and Schmidt (2001) identified some symptoms such as sweaty palms, dizziness, and shortness of breath and heart palpitation as indicators of computer anxiety.

In another study, Bourne (2005) summarized those biological, behavioral, and perceived feelings of persons with anxiety disorders, possibly leading to computerphobia. According to Bourne (2005), four or more of the following symptoms indicate an anxiety disorder: Shortness of breath, heart palpitations, shaking or trembling, sweaty palms, choking, nausea, numbness, dizziness, feeling of detachment, hot flashes or chills, fear of dying and fear of going out of control.

Bourne (2005) also draws attention to the following perceived feelings, which could be considered as the symptoms underlying the occurrence of specific phobias:

1) Fear of losing control

2) Fear of failure

3) Fear of not being able to cope

4) Fear of rejection or abandonment

5) Fear of death and disease

In addition to these indicators, the following are articulated as the indicators of computerphobia:

- Resistance to thinking about or talking about computers

- Anxiety and fear of computers

- Hostile or aggressive actions or feelings towards computers

- Fear of harming computers

- Fear of physical presence of computers

- Avoidance of computer-savvy people

- Resistance to using computers

- Avoidance of using computers

- Fear of failure in computer related tasks (i.e., Bourne 2005, Jay, 1981; Kuşkaya-Mumcu \& Altun, 2008; Maren, 1987; Wilcocks \& Mason, 1987).

The research shows that teachers have noticeably high levels of computer anxiety (Beckers \& Schmidt, 2001; Deniz, 2007; Korobili, Togia, \& Malliari, 2010; Levine \& Donitsa-Schmidt, 1998; Rosen \& Weil, 1995; Thorpe \& Brosnan, 2007; Wilson, 1999). Thus, treating computerphobia includes very early interventions and requires professional help. School is one environment in which unreasonable fears and anxiety-related behavior can be coped with by well-informed professionals such as teachers. As in mathematics anxiety, teachers are likely to transfer their fear about computers to their students. Teachers transfer their fear or attitude to their students and computerphobia is no exception. Modern society needs well-equipped teachers for technologically advanced adults, to serve their administrative, facilitative and pedagogical usefulness.

Thus, this study proposes a novel instrument to measure computerphobia and determine level and interrelations of some extraneous variables such as gender and computer experiences with computerphobia. The following research questions are investigated within the scope of this research:

1) What groups of computerphobia levels can be created by their CPS scores of preservice teachers?

2) Do computerphobia levels differ with gender?

3) Does frequency of computer use make a difference in computerphobia?

4) Do computerphobia levels differ with computer training?

\section{Method}

One of the suitable research methods for determining the computerphobia levels of preservice teachers is descriptive. The study is quantitative in nature and has a relational component. Instrument development and a 
large-scale administration are application aspects of the study.

\subsection{Participants}

829 Participants were selected among education majors in a small northeastern university in Turkey. The freshmen and sophomore students in the sample were selected among those who consented to be included in the study and registered to a college-wide introductory computer course. Gender distribution was $49 \%$ female $(\mathrm{n}=407)$ and $51 \%$ male $(\mathrm{n}=422)$ and ages ranged from 18 to 24 among those who provided their demographic information. Freshmen made up of $76 \%(\mathrm{n}=630)$ while sophomores made up $24 \%$ of the sample.

\subsection{Instruments}

Several instruments are available to measure computer anxiety (Rosen, Sears, \& Weil, 1989; Heinssen, Glass, \& Knight, 1987). An investigation of these instruments reveals that the computerphobia statements are mixed with anxiety related items. A Likert-type multiple choice self-report instrument is developed to measure preservice teachers' computerphobia. The participants are asked to provide the best choice for the statements and the choices are strongly disagree (1), disagree (2), can't decide (3), agree (4), and strongly agree (5). The items in the instrument, Computerphobia Scale (CPS) are created using the psychological and cognitive definitions and indicators for computerphobia in the literature. Earlier research cited above is used to determine the indicators, and benchmarks or observable characteristics of computerphobia are used to develop the instrument. Then symptoms are concretized and clarified for understanding. A group of experts rated the items in the pool and the highest rated items formed the first draft of the instrument. A pilot study is carried out with 27 -item first draft instrument with 130 students. After the initial data analysis, three items are removed from the instrument since their item-total correlations are found to be less than 0.25 . The instrument is finalized with 24 items.

\subsubsection{Reliability and Validity}

The instrument produces a total maximum point of 110 and a minimum point of 24, 67 being the mid-point where the higher scores refer greater computerphobia. The participants completed the measure including CPS and a demographic form in one class session without a time limit. Cronbach alpha reliability coefficient is .87 for the instrument. Four sub-constructs are extracted by a plausible exploratory factor analysis $(\mathrm{KMO}=.889$, Bartlett Sphericity $=.000$ ) explaining, and their reliability coefficients are displayed in Table 1.

Table 1. Number of items and reliabilities for each construct

\begin{tabular}{lcc}
\hline Factor & No. Items & Reliability \\
\hline Fear of Computers & 7 & 0.80 \\
Fear of Failure & 6 & 0.80 \\
Disbelief in computers & 7 & 0.69 \\
Computer usefulness disbelief & 4 & 0.45 \\
\hline
\end{tabular}

In order to validate the factorial structure of the instrument, a CFA was conducted. When interpreting the CFA results, absolute fit indices were taken into account. The values indicated that the model can be regarded as a good fit $(\mathrm{x} 2(246, \mathrm{~N}=726)=1565.33, \mathrm{p}=0.000$, RMSEA $=0.080)$, since RMSEA value of 0.080 or lower are generally regarded as indicative of good fit (Stevens, 2009).

\subsection{Data Analysis}

Categorization of phobia levels via z-values is one of the ways to label cases with data from the reliable instruments (Rosen \& Weil, 1995; Ursavas \& Karal, 2009). Z-values are calculated and computerphobia levels are grouped accordingly. An analysis of variance is conducted to see how computerphobia levels change with independent variables such as in gender, subject area, computer ownership and evaluation of past computer education experiences.

\section{Results}

In this study, computerphobia levels of preservice teachers are investigated in relation to gender and computer experiences. Participants' grand mean from the instrument is 51.67 (sd. 14.73). Distribution of $\mathrm{z}$ scores presents a scheme for computerphobia among education majors. The results are displayed in Table 2. CPS scores provide a general measure for computerphobia, while z-scores indicate the level of phobia in particular distribution. When the CPS score is at least one standard deviation less than the mean of the population, we concluded that 
the participant has no phobia, i.e. very little fear of computers, no or minimal complications with computers and friendly interaction. The score shows a low level of phobia when it is one to two standard deviations greater than the mean. High level is characterized by a score more than three standard deviations greater than the mean.

Table 2. Descriptive findings about computerphobia

\begin{tabular}{lcccc}
\hline Phobia level & Z score & CPS Score & N & Percent \\
\hline No phobia & $<1$ & $22-66$ & 693 & 83.6 \\
Low & $>1$ and $<2$ & $67-81$ & 110 & 13.2 \\
Medium & $>2$ and $<3$ & $82-95$ & 24 & 2.9 \\
High & $>3$ & $96-110$ & 2 & 0.3 \\
\hline
\end{tabular}

Demographic information reveals some significant results. Gender, computer ownership, perceived quality of computer training and evaluation of computer courses are investigated in relation to CPS scores.

\subsection{Computerphobia with Gender and Computer Experience}

A one-way ANOVA is conducted to seek answers to research questions 2, 3 and 4 . The overall test suggests the null hypothesis can be rejected $(\mathrm{F} 9,822=32.156, \mathrm{p}<.001)$. Tests for main effects of computer ownership ( $\mathrm{F} 1$, $822=9.151, \mathrm{p}<002)$, computer usage frequency $(\mathrm{F} 3,822=19.523, \mathrm{p}<.001)$, and perceived quality of computer training $(\mathrm{F} 1,822=22.726, \mathrm{p}<.002)$ produce statistical significance to reject the null hypotheses, implying a difference in groups. Detailed findings can be found in Table 3.

Table 3. Means, standard deviations and ANOVA results for CPS scores

\begin{tabular}{lccccc}
\hline Variable & N & Mean & SD & F & p \\
\hline Gender & & & & & \\
Male & 422 & 49.66 & 14.49 & 6.271 & .013 \\
Female & 406 & 53.82 & 14.71 & & \\
\hline Computer Ownership & & & & 9.151 & .003 \\
\hline Yes & 359 & 47,41 & 14.22 & & \\
No & 468 & 54.94 & 14.27 & & .000 \\
Computer use frequency & & & & \\
Everyday & 220 & 43,46 & 13,11 & & .000 \\
Few times a week & 485 & 52,86 & 13.43 & & \\
Few times a month & 102 & 61,17 & 13.17 & & \\
Few times a year & 15 & 69.13 & 22.02 & & \\
\hline Perceived quality of computer training & & & \\
\hline Very low & 185 & 57.96 & 15.61 & & \\
Low & 208 & 55.58 & 12.80 & & \\
Medium & 293 & 50.00 & 13.57 & & \\
good & 116 & 41.74 & 12.01 & & \\
Very good & 20 & 35.70 & 10.34 & & \\
\hline
\end{tabular}

According to Table 3, females have significantly more computer fear than males, as shown by the mean values 
$(\mathrm{Xm}=49.66, \mathrm{Xf}=53.82 ; \mathrm{F} 1,822=6.271, \mathrm{p}<.013)$.

\subsection{Computer Ownership}

One demographical question asks "Do you currently own a computer for your use only?" Responses to this question show $43 \%$ of the participants say "yes" while $57 \%$ do not have computers of their own. Participants who own computers have significantly lower scores of CPS indicating less computerphobia.

\subsection{Computer Usage Frequency}

Computer usage data is gathered from the responses to the question: "On average, how frequently do you use computers?" Data indicate that $27 \%$ of education majors use computers everyday while $59 \%$ use computers a couple of times per week. The rates of participants who use computers a few times per month and a few times per year are $12 \%$ and $2 \%$, respectively. Teacher candidates who use computers more frequently have lower scores on CPS. Post-hoc tests are also performed to pin down the differences within groups. According to Table 4, preservice teachers who report their computer usage a few times per year and a few times per month are not significantly different in CPS scores. Other groups, namely everyday users and weekly users, have different scores from each other as well as monthly and annual users.

\subsection{Computer Training}

Participants" responses are collected with the question "How do you evaluate your computer training in past computer courses before you began attending university?". The choices range from very low, low, moderate, adequate to very good. The results show that the participants who received low quality computer training have greater computerphobia.

Comparisons of CPS scores for participant responses about their computer training reveal three distinct groups. Participants receiving medium computer training scored significantly different than both low categories (very low and low) and high categories (very good and good) while both lower and better categories are not different. Expectedly, CPS scores reversely related to computer training.

\section{Discussion}

This study proposes an instrument to measure computerphobia to help determine the individuals with phobia reaching at psychopathological levels. One of the major findings in this study is that about $.3 \%(\mathrm{f}=2)$ of the participants have phobic reactions towards computers at the psychopathological level and require serious attention and probably psychological help according to DSM IV guidelines (Thorpe \& Brosnan, 2007). These participants experience a high level of fear and anxiety towards computers and they resist thinking or talking about computers. They probably engage hostile and aggressive behavior and they avoid using computers or getting technical support. It is important to make them feel secure by implementing anxiety-reducing interventions (Rosen, Sears, \& Weil, 1989).

A total of $2.9 \%$ of the participants suffer from moderate computerphobia. Although this rate can be considered slightly lower than what some studies reported, participants in these categories may develop a more serious type of phobia and reach clinical levels, and consequently, avoid adapting new technologies (Anthony, Clarke, \& Anderson, 2000).

The percentage of the participants who somewhat have computerphobia totals up to $16.4 \%$. There are studies in the literature that agree (Agbatogun \& Banjo, 2010; King, Bond, \& Blandford 2002; Mcllroy, Sadler, \& Boojavon, 2007; Bourne, 2005; Tekinarslan, 2008), and contradict (Arigbabu, 2006; Anthony et al., 2000) with the results of this study since various studies report a lower rate of computerphobic individuals in their sample.

There are conflicting reports on gender differences in computerphobia. This study shows that males have significantly less computerphobia than females. The results agree with some of the earlier research (Agbatogun \& Banjo, 2010; Deniz, 2007; while conflicting with some others (Laguna \& Babcock, 1997).

Computer ownership is reported to be one of the factors reversely related to computerphobia (Rosen \& Weil, 1995), although Deniz (2007) reports otherwise. Data analysis in this study indicates significantly different CPS scores when a computer is present in participants' life. Usually, a person with a specific phobia avoids the situation where they face an anxiety-generating stimulus. This avoidance, in turn, becomes a habit where keeping away from computers is rewarding. On the other hand, presence of computers may reduce the anxiety and computerphobia in time (Bourne, 2005).

Both computer usage frequency and computer training are reported in the literature to decrease anxiety, and phobia as well (Levine \& Donitsa-Schmidt, 1997; Bozionelos, 2001; Todman \& Drysdale, 2004). It may be concluded that the direction of the relationship remains unknown, but there is some evidence that using more 
computers may cure phobia (Todman \& Drysdale, 2004).

\subsection{Implications}

Teacher candidates should be examined periodically for several reasons. First, they themselves are individuals at the workplace and are more exposed to computers for maintaining administrative, personal or educational tasks. Second, they tend to communicate their psychological, behavioral or cognitive characteristics with their students. Third, when computerphobia uncontrollably increases, it may lead to other types of phobias and psychopathology becomes clinical (Bourne, 2005; Thorpe \& Brosnan, 2007).

The results suggest that the teacher candidates demonstrate reduced computerphobia when they; a) own a computer, b) use a computer frequently, and c) receive adequate computer training. It may be important to provide preservice teachers with opportunities to expose them to computers, and to review computer education approaches for more meaningful and anxiety-reducing experiences. There is a need for research efforts to deeply understand the factors that create the fear and comprehensively investigate the techniques to prevent and treat when diagnosed.

\section{Acknowledgments}

Special thanks to Arif Altun for his valuable input and significant contributions.

\section{References}

Agbatogun, A. O., \& Banjo, B. (2010). Computer efficacy, use, and phobia: Contributions to Nigerian undergraduates' academic performance in a computer graphics course. Pacific Journal of Science and Technology, 11(1), 362-372.

Anthony, L. M., Clarke, M. C., \& Anderson, S. J. (2000). Technophobia and personality subtypes in a sample of South African university students. Computers in Human Behavior, 16, 31-44. http://dx.doi.org/10.1016/S0747-5632(99)00050-3

Arigbabu, A. A. (2006). Evidence of computerphobia in Nigerian education majors. Pshychological Reports, 98 , 433-436. http://dx.doi.org/10.2466/pr0.98.2.433-436

Baloglu, M., \& Cevik, V. (2009). A multivariate comparison of computer anxiety levels between candidate and tenured school principals. Computers in Human Behavior, 25, 1102-1107. http://dx.doi.org/10.1016/j.chb.2009.05.007

Beckers, J. J., \& Schmidt, H. G. (2001). The structure of computer anxiety: A six-factor model. Computers in Human Behavior, 17, 35-49. http://dx.doi.org/10.1016/S0747-5632(00)00036-4

Bourne, E. J. (2005). The Anxiety and Phobia Workbook. New Harbinger Publications: Oakland, CA.

Bozionelos, N. (2001). Computer anxiety: Relationship with computer experience and prevalence. Computers in Human Behavior, 17, 213-224. http://dx.doi.org/10.1016/S0747-5632(00)00039-X

Carlson, C., \& DiLillo, A. V. (2001). Lessons learned: Transcending computerphobia. American Journal of Nursing, 101(10), 24A-C.

Deniz, L. (2007). Prospective class teachers' computer experiences and computer attitudes. International Journal of Social Sciences, 2(2), 116-122.

Fisher, M. (1991). Computerphobia in adult learners. Computer Education, 14-19.

Gordon, M., Killey, M., Shevlin, M., McIlroy, D., \& Tierney, K. (2003). The factor structure of the Computer Anxiety Rating Scale and the Computer Thoughts Survey. Computers in Human Behavior 19, 291-298. http://dx.doi.org/10.1016/S0747-5632(02)00061-4

Heinssen Jr., R., Glass, C, \& Knight, L. (1987). Assessing computer anxiety: Development and validation of the Computer Anxiety Rating Scale. Computers in Human Behavior, 3, 49-59. http://dx.doi.org/10.1016/0747-5632(87)90010-0

Hudiburg, R. A. (1990). Comparing computer-related stress to computerphobia. ERIC Document. ED 318986.

Jay, T. B. (1981). Computerphobia: What to do about it? Educational Technology, 21(1), 47-48.

King, J., Bond, T., \& Blandford, S. (2002). An investigation of computer anxiety by gender and grade. Computers in Human Behavior, 18, 69-84. http://dx.doi.org/10.1016/S0747-5632(01)00030-9

Korobili, S., Togia, A., \& Maliari, A. (2010). Computer anxiety and attitudes among undergraduate students in Greece. Computers in Human Behavior, 26, 399-405. http://dx.doi.org/10.1016/j.chb.2009.11.011 
Kuskaya-Mumcu, F., \& Altun, A. (2008). Teknofobi. In D. Deryakulu (Ed.), Bilişim Teknolojileri Öğretiminde Sosyo-Psikolojik Değişkenler. Maya Akademi: Ankara.

Laguna, K., \& Babcock, R. L. (1997). Computer anxiety in young and older adults: Implications for human-computer interactions in older populations. Computers in Human Behavior, 13, 317-326. http://dx.doi.org/10.1016/S0747-5632(97)00012-5

Levine, T., \& Donitsa-Schmidt, S. (1997). Computer use, confidence, attitudes and knowledge: A causal analysis. Computers in Human Behavior, 14, 125-146. http://dx.doi.org/10.1016/S0747-5632(97)00036-8

Lynn, M. H. (1989). Computerphobia in community college students: Identifying adults "at-risk". (Unpublished Dissertation). Pepperdine University, Malibu, CA.

Maren, J. (1987). Computer literacy and the older learner: a computer department's response. ACM SIGCSE Bulletin, 19(3), 25-28. http://dx.doi.org/10.1145/36093.36102

Mcilroy, D., Sadler, C., \& Boojawon, N. (2007). Computerphobia and computer self-efficacy: Their association with undergraduates' use of university computer facilities. Computers in Human Behavior, 23, 1285-1299. http://dx.doi.org/10.1016/j.chb.2004.12.004

Rosen, L. D., \& Weil, M. M. (1995). Computer anxiety: A cross cultural comparison of university students in ten countries. Computers in Human Behavior, 11(1), 45-64. http://dx.doi.org/10.1016/0747-5632(94)00021-9

Rosen, L. D., Sears, D. C., \& Weil, M. M. (1989). The model computerphobia reduction program: A longitudinal evaluation. ERIC Document. ED318467.

Stevens, J. (2009). Applied Multivariate Statistics for the Social Sciences (5th ed.). New York: Taylor \& Francis, Inc.

Tekinarslan, E. (2008). Computer anxiety: Across-cultural comparative study of Dutchand Turkish university students. Computers in Human Behavior, 24, 1572-1584. http://dx.doi.org/10.1016/j.chb.2007.05.011

Thorpe, S. J., \& Brosnan, M. J. (2007). Does computer anxiety reach levels which conform to DSM IV criteria for specific phobia? Computers in Human Behavior, 23, 1258-1272. http://dx.doi.org/10.1016/j.chb.2004.12.006

Todman, J., \& Day, K. (2006). Computer anxiety: The role of psychological gender. Computers in Human Behavior, 22, 856-869. http://dx.doi.org/10.1016/j.chb.2004.03.009

Todman, J., \& Drysdale, E. (2004). Effects of qualitative differences in initial and subsequent computer experience on computer anxiety. Computers in Human Behavior, 20(5), 581-590. http://dx.doi.org/10.1016/j.chb.2004.03.028

Ursavas, O. F., \& Karal, H. (2009). Assessing pre-service teachers' computerphobia levels in terms of gender and experience, Turkish sample. International Journal of Behavioral, Cognitive, Educational and Psychological Sciences, 1(1), 71-75.

Wilcocks, L., \& Mason, D. (1987). Computerising Work. London: Paradigm Publishing.

Yaghi, H. M., \& Abu-Saba, M. B. (1998). Teachers' computer anxiety: An international perspective. Computers in Human Behavior, 14(2), 321-336. http://dx.doi.org/10.1016/S0747-5632(98)00010-7

\section{Copyrights}

Copyright for this article is retained by the author(s), with first publication rights granted to the journal.

This is an open-access article distributed under the terms and conditions of the Creative Commons Attribution license (http://creativecommons.org/licenses/by/3.0/). 